immediate affairs then took two weeks to conclude. Once back at work, I was told that one week was to be defined as 'Compassionate Leave' and the other week was to be 'Annual Leave'!

Several people wondered why I hadn't just phoned in sick! Well, I wasn't sick and at such times, one's mind is hardly on such strategies. I had always assumed subconsciously that an employer like the NHS would be wholly supportive at such times.

Once I returned, the occupational health staff asked if I had read the Trust's Special Leave Policy and considered that the second week should have been defined as 'Carer's Leave' to which it appeared I was entitled. I raised this with the manager who steadfastly declined to change the position and decision.

On those grounds, I raised a Grievance and with the able assistance of the BDA, took it through the two of the three internal stages/hearings without success. This did little to assist a grieving process and in July 2005, my mother passed away. I was then signed off by my GP for what turned out to be seven weeks to close her affairs.

The third stage hearing was held after I returned to work and involved another manager who finally found in my favour. Not surprisingly, the fourth and final stage of the Grievance would have involved an external panel.

At that final hearing, the manager concerned opened proceedings by asking me brightly 'So how is your mother now...?' and after I answered, 'Did you get Compassionate Leave this time?'

It was one of several factors which contributed in 2008 to me leaving not only that post but also the NHS after 24 years service.

R. D. B. Dickson By email

DOI: 10.1038/sj.bdj.2011.776

\section{OUT OF TOUCH}

Sir, I am writing to you in response to the letter titled Evidenced by experience by A. E. Castle (BDJ 2011; 211: 153) I would like to make a few points here as the author seems to be out of touch with the current concepts in evidencebased dentistry.
I would like the author to read the NICE guidelines on reviewing and grading evidence. ${ }^{1}$ As per the guidelines, evidence by experience is the least valid of all the evidence levels.

A. E. Castle recommends that zinc oxide eugenol-based liners are used under amalgam restorations. For most clinicians, dental school provides the first introduction to these materials, and some clinicians continue to use the materials first introduced when they were in school. It seems that 50 years ago ZOE was the liner of choice and the author has stayed loyal to it. Presently liners are no longer routinely used under all amalgam restorations except for those very close to the pulp. ${ }^{2,3}$ A. E. Castle says that 'DYCAL is not able to withstand the condensation pressure of packing the amalgam'. This statement is wrong, as currently available DYCAL is able to withstand the condensation pressure as per the manufacturer's guidelines. ${ }^{4}$

Finally the letter writer says that 'application of Duraphat varnish to the perimeters of the cavity prior to inserting the amalgam will leave it with an effective seal'. Duraphat is soluble in saliva and oral fluids and it will in no time leach out of the margins of the restoration and leave the restoration susceptible to micro-leakage. It would be irresponsible on the part of the dentist to attempt such an experimental use of Duraphat varnish for which there is no such manufacturer recommendation or any evidence.

A. E. Castle justifies it as evidencebased as s/he has used it successfully, but I don't know what parameter s/he used to measure the success.

\section{Z. Imran}

Dundee

1. NICE: Guideline Development Methods. Available at: http://www.nice.org.uk/niceMedia/pdf/GDM_ Chapter7 0305.pdf

2. Cox C F, Suzuki S. Re-evaluating pulp protection: calcium hydroxide liners vs. cohesive hybridization. J Am Dent Assoc 1994: 125: 823-831.

3. Weiner R S, Weiner L K, Kugel G. Teaching the use of bases and liners: a survey of North American dental schools. J Am Dent Assoc 1996; 127: 1640-1645.

4. Dentsply product details. Dycal. http://www. dentsply.co.uk/Products/Restorative/Cements/ Dycal.aspx

DOI: 10.1038/sj.bdj.2011.777 